\title{
Origem, causas e impactos da crise financeira de 2008
}

\author{
Alícia Cechin" \\ Marco Antonio Montoya**
}

\begin{abstract}
Resumo
A crise demonstra uma situação anormal, pois ela não rompe apenas com a prosperidade recebida e desfrutada até o momento, mas também cria um conjunto de escassez e de dificuldades para a grande maioria dos envolvidos. A ocorrência de uma crise financeira pode-se entender resumidamente como conturbações na economia, fundamentadas por eventos econômicos. A crise de 2008 representou uma mudança na história do capitalismo, atingiu todos os mercados, do monetário ao de crédito, das bolsas de valores à de mercadorias. Ela alcançou o âmbito internacional e foi muito intensa, gerando um indício da escassez global de liquidez em dólares e tornando pior os termos de troca, devido à queda dos preços das commodities. A bolha financeira americana foi considerada a maior, desde a grande depressão de 1929.
\end{abstract}

Palavras-chave: Causas. Consequências. Crise de 2008. Impactos.

* Doutoranda do Programa de Pós-Graduação em Economia Aplicada, da Universidade Federal de Viçosa (UFV). E-mail: alicia_cechin@hotmail.com

** Doutor em Economia Aplicada. Professor Titular da Faculdade de Ciências Econômicas, Administrativas e Contábeis da Universidade de Passo Fundo (Feac-UPF). E-mail: montoya@upf.br

http://dx.doi.org/10.5335/rtee.v23i48.7363

Submissão: 01/07/2016. Aceite: 04/04/2017. 


\section{Introdução}

A conceituação técnica da palavra crise é demonstrada a partir do ponto de inflexão na fase ascendente do ciclo, momento em que a expansão é rompida e, com isso, inicia-se uma etapa com características contrárias, como descreve Accurso (1983). A crise demonstra uma situação anormal, pois ela não rompe apenas com a prosperidade recebida e desfrutada até o momento, mas também cria um conjunto de escassez e dificuldades para a grande maioria dos envolvidos, como ilustra o autor.

A crise do subprime, que foi nomeada também de crise bancária, crise de 2008, crise da bolha imobiliária, crise financeira, dentre outras definições, teve início em meados de 2007, mas só se tornou uma crise global em 2008 e representou uma mudança na história do capitalismo. Conforme Bresser-Pereira (2010), a crise de 2008 não começou, diferentemente do que costumam ser as crises financeiras nos países ricos, causada principalmente pela desregulação dos mercados financeiros e pela forte especulação. Destaca que o marco para essa crise foi a desregulação, sustentada pela ideia de que, no período de 2001/2002, a política monetária do $\mathrm{Fe}$ deral Reserve Bank (FED), manteve suas taxas de juros baixas por um longo tempo e, com isso, provocou um aumento na oferta de crédito.

O início da crise financeira geral pode ser dado a partir da crise dos subprimes ou, mais especificamente, das hipotecas. Essas foram proporcionadas a clientes com baixa qualidade de crédito. De acordo Bresser-Pereira (2010), as mesmas juntaram-se a títulos abstrusos e opacos, dificultando a avaliação dos compradores. Esse problema, ocorrido em um pequeno setor, não deveria ter tomado tamanha proporção. O impactante é que, nos anos anteriores, o sistema financeiro internacional foi unido a operações financeiras securitizadas, que possuíam uma relevante fragilidade; em suma, as suas novidades e inovações, que ocasionaram especulações, tornaram o sistema arriscado.

Com o aumento dos contratos com inadimplência, que foram à execução, os preços dos imóveis entraram em um período de queda, de acordo com Freitas (2008). Com a integração financeira em crescimento desde o ano de 1980, a crise, que teve início no mercado hipotecário, logo se espalhou para diferentes mercados financeiros dos Estados Unidos e do restante do mundo, conforme descreve a autora. A incerteza em relação ao risco, fez com que os bancos tivessem preferência pela liquidez, diminuindo os empréstimos no mercado interbancário e reduzindo a concessão de crédito para os clientes, até mesmo os de baixo risco. 
A crise de 2008, que ficou conhecida pela sua severidade dentre as economias capitalistas desde 1929, como esclarece Bresser-Pereira (2010), foi considerada também uma crise social. Informações da Organização Internacional do Trabalho (OIT), mostram que o número de desempregados passou de 20 milhões para 50 milhões de pessoas no final de 2009.

O processo de globalização fez com que a instabilidade gerada ou iniciada em uma economia conseguisse se espalhar por outras economias com facilidade, como relata Lobão (2007). A integração entre as economias, como enfatiza, permite a exposição às influências externas. O efeito contágio faz com que as instabilidades econômicas não se limitem apenas ao país de origem, mas se espalhe no mercado mundial de diferentes formas e dimensões estruturais.

Frente aos fatos acima destacados, o objetivo da pesquisa insurge, no levantamento histórico, do aparecimento da crise de 2008 e dos seus consequentes impactos no mercado mundial. Para tanto, utiliza-se a pesquisa bibliográfica como metodologia e suporte teórico.

O presente estudo estrutura um referencial teórico subdividido nas seguintes sessões: na segunda seção, destacam-se os principais fatos ocorridos nos anos anteriores a eclosão da crise, elucidando sua origem; na terceira seção, traz-se a construção da bolha financeira e a participação das instituições privadas na crise de 2008; na quarta seção relata-se a expansão da crise no mercado mundial, destacando os incentivos recebidos, com o intuito de amenizá-la a suas consequências no mercado mundial; e, posteriormente, faz-se as considerações finais.

\section{A origem da crise}

A ocorrência de uma crise financeira se pode entender facilmente como conturbações na economia, que são fundamentadas em eventos econômicos, conforme relatam Reinhart e Rogoff (2009); ou, em limites quantitativos, podem ser crises inflacionárias ou hiperinflacionárias e cambiais. Kaminsky e Reinhart (1996) elucidam que uma crise cambial pode ser definida como um momento em que ocorre um ataque sobre a moeda, conduzindo a uma perda substancial das reservas internacionais ou, também, a uma forte depreciação cambial.

Kaminsky e Reinhart (1996) chamam atenção para o fato de que se uma crise pode ser instaurada por um evento bem definido, como a depreciação cambial, esse evento não é pré-requisito para ocorrência de uma crise. Quando se trata de crise bancária, relatam que seu início é marcado por corridas bancárias, que levam ao encerramento de inúmeras instituições financeiras. Caso o fechamento não ocorra, 
inicia-se os processos de fusões e aquisições ou de assistência, em grande escala, por parte do governo, com o objetivo de assegurar e de manter as instituições de grande importância financeira.

No decorrer dos últimos anos, um fato relevante das crises financeiras, como mencionam os autores, é a sua capacidade de atingir outras economias que não a de sua origem, que a literatura se denomina de efeito contágio. Conforme Kaminsky e Reinhart (1996), o efeito contágio refere-se ao caso em que a ocorrência de uma crise cambial em outro país faz com que aumente a probabilidade de uma crise na economia doméstica. Já para Kaminsky, Reinhart e Végh (2003), o efeito contágio pode ser definido como um acontecimento em que um evento tem uma série de ocorrências imediatas em vários países, quando tem consequências rápidas, evolui em questão de horas ou dias.

Lin, Engle e Ito (1991) relatam que, frente a crescente integração dos mercados, o contágio é conhecido como forma de propagação da volatilidade dos preços dos ativos financeiros de uma economia em crise para os mercados financeiros de outras economias. Uma mudança considerável consiste na psicologia de mercado, em que as informações são transmitidas de um mercado a outro, de modo a influenciar as decisões dos agentes.

Posto que a crise do subprime tenha assumido uma forma turbulenta, a mesma se enquadra no processo de reversão do terminativo ciclo das construções residências dos Estados Unidos, que teve seu início em 1994, como destaca Gontijo (2008), quando apresentou um aumento nos preços reais das residências, mesmo que um aumento vagaroso, devido à queda que houve nos anos anteriores (1990 a 1993). O autor menciona que, embora escassa a sensibilidade em relação à renda corrente, a construção residencial e todos os seus ciclos, possuem alta dependência dos créditos habitacionais.

As residências representam bens de capital, para quem aluga, e bens de consumo de longa duração, para quem pretende adquiri-las para o seu próprio uso, isso explica por que a literatura admite que a taxa de juro (política monetária), exerça forte influência sobre o ciclo da construção. Gontijo mostra que tentativas de abordar esse mercado como mercado de ativos financeiros vêm trazendo um elevado grau de dificuldade:

A reestruturação do sistema financeiro habitacional norte-americano provocada pela liberalização financeira e pelo desenvolvimento de securitização de títulos hipotecários a partir de meados da década de 1980 tornou o mercado habitacional norte-americano integrado ao mercado de capitais (2008, p. 9). 
Se analisada a evolução do mercado habitacional dos Estados Unidos, verifica-se uma relação entre o ciclo da construção e as condições do crédito habitacional. Os mesmos tiveram alterações consideráveis nos últimos 80 anos, devido às crises ocorridas no período. Gontijo (2008) mostra fatos importantes desse mercado, ocorridos desde 1920:

a) em 1920, era grande a ocorrência de empréstimo hipotecário de curto prazo (entre três e cinco anos);

b) em 1932, o Congresso Norte-Americano criou o Federal Home Loan Bank ${ }^{1}$, iniciado com 11 bancos e depois criando mais um, teve como objetivo ajudar as instituições que financiavam as residências, o mesmo tinha a supervisão do Home Loan Bank Board;

c) no ano seguinte, em 1933, o Congresso criou o Home Owners Loan Corporation (HOLC), com a finalidade de fazer empréstimos com prazo de até 15 anos;

d) em 1935, iniciaram-se as compras das hipotecas de propriedades comerciais urbanas, regulamentadas pela Reconstruction Finance Corporation ${ }^{2}$;

e) no ano de 1938, foi aprovada a legislação que autorizava o governo a patrocinar esse mercado. Nesse mesmo ano, foi criada a Federal National Mortgage Association ${ }^{3}$ (FNMA ou Fannie Mae), que iniciou o processo de compra das hipotecas asseguradas pela Federal Housing Administration ${ }^{4}$ (FHA);

f) em 1941, o Congresso aprovou o sexto título do National Housing Act ${ }^{5}$,que passou a fazer a cobertura de áreas militares e, posteriormente, de agências habitacionais federais;

g) no ano de 1944, o Servicemen's Readjustment Act ${ }^{6}$ forneceu meios de obtenção de crédito hipotecário aos veteranos da Guerra, através da Veterans' Administration $^{7}$ (VA). Após a Segunda Guerra Mundial, coberta pelo sexto título, as residências foram vendidas a preços baixos para esses soldados mais velhos e para pessoas ligadas a programas nucleares;

h) no período entre 1935 e 1952, cerca de 4,25 milhões de residências foram financiadas através de créditos hipotecários, que eram garantidos pela FHA e a VA, correspondendo a $40 \%$ das novas residências construídas;

i) em 1970, o Federal Home Bank Board ${ }^{8}$ criou a Federal Loan Mortgage Corporation $^{9}$ (Feddie Mac), que possuía permissão para vender hipotecas das Savings\&Loan ${ }^{10}$, não garantidas pela FHA e VA;

j) em 1979, com o aumento das taxas de juros e com a política monetária feita por Paul Volker, iniciou-se a perda expressiva de recursos, principalmente, 
do Savings\&Loan, quando seus depositantes fizeram a transferência do seu dinheiro para lugares com maior rentabilidade;

k) entre os anos de 1986 e 1989, a Federal Savings and Loan Insurance Corporation $^{11}$ (FSLIC) fez a intervenção/fechamento de 296 instituições, operação envolvendo US $\$ 125$ bilhões.

l) depois da crise de 1991-1992, a recuperação da construção residencial foi consequência das transformações estruturais que ocorreram no mercado hipotecário, em que se pode notar o surgimento das hipotecas securitizadas, chamadas de Mortagage-Backed Securities ${ }^{12}$ (MBSs) ou de Residential Mortagage-Backed Securities ${ }^{13}$ (RMBSs).

Gontijo (2008) relata que, entre os anos de 1980 e 1994, em torno que 1.600 bancos, que possuíam a seguridade do Federal Deposit Insurance Corporation ${ }^{14}$ (FDIC), foram fechados ou receberam ajuda da Corporação. A totalidade dos custos que a crise somou, entre os períodos de 1986 a 1996, foi de cerca de US\$1.601,1 bilhões, evidenciando que, de todo esse valor, coube ao governo norte-americano arcar com cerca de US $\$ 124,6$ bilhões.

A contração do sistema financeiro e da construção residencial teve uma queda de residências construídas de 1,8 milhão de unidades, em 1986, para um milhão no ano de 1991, situação que contribuição para a fase recessiva de 1990-1991. Gontijo elenca, entre as vítimas institucionais da crise de 2008, a FSLIC, pois, quando se tornou insolvente, foi recapitalizada inúmeras vezes com valores de US\$ 15 bilhões, no ano de 1986, e mais de US\$10,75 bilhões no ano seguinte.

Tanto a FSLIC quanto o Federal Home Loan Bank Board (FHLBB) foram abolidos pelo Financial Institutions Reform, Recovery and Enforcement Act (FIRREA) de 1989, que instituiu o Office of Thrift Supervision (OTS), um bureau do Departamento do Tesouro encarregado de autorizar, regular, examinar e supervisionar as instituições de poupança, e o Federal Housing Finance Board (FHFB), agência independente de supervisão dos doze Federal Home Loan Banks (também chamados bancos distritais). A FSLIC foi substituída pelo Savings Association Insurance Fund (SAIF), encarregado de assegurar as instituições de poupança administradas pela Federal Deposit Insurance Corporation (FDIC). O FIRREA também deu à Freddie Mac e à Fannie Mae responsabilidades adicionais para apoiar o crédito hipotecário para as famílias de baixa e moderada renda (2008, p. 14).

Foi a partir de 2003, com a intensificação de transações no mercado imobiliário dos Estados Unidos e com o aumento das concessões de empréstimos mobiliários para tomadores com alto risco, que os bancos intensificaram as movimentações sem registros nos balanços, como mostra Freitas (2008). Os bancos transferiram para os SIV (veículos de investimento estruturados) uma parte da sua carteira de empréstimo subprime, com o objetivo de evitar os requerimentos de capital ligados

Teoria e Evidência Econômica - Ano 23, n. 48, p. 150-171, jan./jun. 2017 
a esses ativos. Foi assim que iniciou a circulação, no mercado financeiro, de instrumentos financeiros lastreados em hipotecas já securitizadas, emitidas pelo SIV e garantidas pelos bancos comerciais, como destaca o autor.

Borça Júnior e Torres Filho (2008) descrevem que o mercado de hipotecas norte-americano atingiu seu auge em 2003, devido à emissão de aproximadamente US\$ 4 trilhões de novas hipotecas. A conservação desse ciclo imobiliário expansionista, até o final do ano de 2006, deve-se a importância do segmento subprime, a partir de 2004, tanto na emissão de novas hipotecas, como no processo de securitização. Desse modo, ressaltam os autores que a sustentação do mercado imobiliário dos Estados Unidos foi atingida, inicialmente, pela inclusão como tomadores de hipotecas de uma parcela de pessoas com menor capacidade de pagamento.

Problemas começaram a surgir em 2006, segundo Freitas (2008), quando o processo contínuo de aumento da taxa de juros pelo FED, desde o final de 2004, fez com que houvesse crescimento na inadimplência dos portadores de hipotecas subprimes. E, com o crescimento da inadimplência desses contratos, os preços dos imóveis iniciaram um movimento de queda. Com consequências graves para o mercado imobiliário, alastrou-se para diversas partes do mercado financeiro dos Estados Unidos e do mundo.

\section{A construção da bolha financeira}

O mercado imobiliário norte-americano passou pelo seu período mais longo de valorização entre 1997 e 2006 . A elevação dos preços dos imóveis foi contínuo, chegando a triplicar o valor, como destacam Borça Junior e Torres Filho (2008). Isso se relaciona ao aumento do crédito imobiliário americano, que foi ancorado em uma redução nas taxas de juros.

Entre os anos de 2000 e 2003, as taxas de juros de longo prazo continuaram a reduzir. Greenspan (2008) relata que os juros dos títulos do Tesouro, em dez anos, tiveram uma redução de $7 \%$ para 3,5\%. Porém, não eram apenas as taxas americanas de juros de longo prazo que estavam despencando, mas também a taxas mundiais seguiam a tendência de queda.

Gontijo (2008) descreve um novo impulso para a redução da taxa de juros, promovida pelo FED, no período em que estourou a bolha do mercado acionário, direcionado praticamente ao setor da tecnologia. A redução da taxa de juros, acrescida do desenvolvimento do método de securitização, e as inovações financeiras inseridas naquele período tornaram o boom do mercado de residências em um verdadeiro delírio, com taxa média de elevação dos preços de 6,4\% a.a. entre 2000/2005. 
Greenspan (2008) ressalta que, no ano de 2003, as taxas de juros dos empréstimos hipotecários de trinta anos eram menores do que $6 \%$ a.a., sendo assim, o nível mais baixo desde os anos de 1960. A partir disso, houve um estímulo à rotatividade dos imóveis, fazendo com que os preços continuassem subindo. O número de famílias que possuíam casa vinha aumentando desde o ano de 1994. No ano de 2006, esse número representava cerca de $69 \%$.

O mercado de hipotecas, no período de 2001 a 2006 , movimentou cerca de US $\$$ 3 trilhões ao ano em novas operações, com destaque para o ano de 2003, que atingiu quase US\$ 4 trilhões, conforme Borça Junior e Torres Filho (2008). O aumento significativo desses valores leva em conta fatores importantes, como a intensa ampliação da escala do mercado hipotecário norte-americano e, também, o aumento do processo de securitização dos créditos subprimes.

Segundo Borça Junior e Torres Filho, o crescimento desse mercado de hipotecas e a securitização dos créditos subprimes "foram financiados, basicamente, pela obtenção de recursos com a venda de títulos no mercado de capitais por ação de agentes privados" (2008, p. 140). A partir disso, os bancos e as corretoras passaram a ser decisivos.

Em meados de 2002, a concorrência existente entre os agentes financeiros que estavam atuando no mercado de hipotecas fez com que se propagasse a utilização dos diferentes tipos de contratos, com a finalidade de atrair os tomadores de maior risco e, consequentemente, os de maior rendimento. Cintra e Cagnin (2007) relatam o oferecimento de uma série de contratos, como: os balloon mortgage, ou interest-only loan, com juros pagos ao longo da vigência do interest-only loan e, depois desse período, além dos juros, a amortização; e as hipotecas híbridas, que já estabeleciam as taxas pré-fixadas no início do contrato e, posteriormente, tornavam-se contratos pós-fixados.

Essas carteiras de crédito tiveram rápida securitização e foram unificadas com um conjunto de ativos financeiros, as chamadas CDO, que, posteriormente, eram revendidas. Cintra e Cagnin (2007) mencionam que as CDO englobavam hipotecas de diferentes riscos, como as que eram recebidas de cartão de crédito, de crédito para a aquisição de automóveis, dentre outras. Essas transações foram estruturadas pelos bancos de investimento e compostas por várias tranches com diferentes graus de risco, classificados pelas agências de risco de crédito.

O mercado imobiliário norte-americano, a partir de 2006, como destacam Cintra e Cagnin (2007), começou apresentar sinais de redução nos preços e na quantidade. A desvalorização dos imóveis aconteceu de ano a ano e de modo acelerado. 
Esses impactos foram sentidos com uma maior expressividade nos segmentos de maior risco do mercado de financiamento habitacional.

O aumento da inadimplência dos devedores de maior risco foi perceptível a partir do encolhimento do mercado imobiliário, que teve repercussão no sistema financeiro do mundo todo, devido as sua ampla abrangência. Cintra e Cagnin relatam que em torno de $90 \%$ das hipotecas subprimes envolveram algum tipo de fraude: "mais da metade dos tomadores superestimaram em mais de 50\% suas rendas. Os agentes financeiros falsificaram informações no sistema eletrônico de pontuação (credit score)" (2007, p. 321) com o objetivo de facilitar as operações e, posteriormente, embolsar a devida comissão.

A crescente inadimplência e a redução dos preços dos imóveis, no ano de 2006, fizeram com que o mercado de MBSs reduzisse, e as carteiras dos bancos originadores acumulassem, que, de acordo com Gontijo (2008), não tinham interrompido sua emissão. Confiantes de que a queda que estava acontecendo no mercado de MBSs era passageira, os bancos incorporaram as SPVs com MBSs arriscadas sem a percepção de que os bancos originadores, em teoria, teriam feito à transferência dos riscos de hipotecas subprimes para as SPVs, e, posteriormente, os investidores voltariam a incorporá-las de forma crescente.

Paralelamente, muitas das instituições financeiras que haviam segurado esses títulos - o que inclui muitos dos próprios bancos originadores - foram compelidos a aumentar as provisões para perdas e/ou a enfrentar calls para pagamento de margens. Em outras palavras, em lugar de recair sobre os investidores, conforme pressupunha o modelo de securitização, as perdas foram se acumulando nas instituições financeiras, particularmente nas originadoras de MBSs e naquelas que asseguravam esses títulos contra as perdas de capital. (GONTIJO, 2008, p. 25).

Gontijo (2008) relata que o problema de inadimplência tornou-se grave, porque as hipotecas exigiam pagamentos adicionais, quando o valor do imóvel ficava abaixo do valor da dívida hipotecária. No primeiro mês de 2008 , havia no mercado cerca de 4 milhões de residências não vendidas, incluindo cerca de 2,9 milhões de residências desocupadas. Esse aumento significativo da oferta de imóveis fez com que o preço dos mesmos reduzisse e a inadimplência aumentasse. Esse fato causou perdas irreparáveis no mercado hipotecário.

Outra implicação do mercado subprime foi o desaparecimento da margem de ganho especulativo imobiliário, que, conforme Borça Júnior e Torres Filho (2009), era a responsável pela sustentação das renegociações de crédito. No lugar de adquirirem novas hipotecas, os credores de subprime se sentiam obrigados a entregar os seus imóveis para pagamentos de dívidas. A participação das instituições 
financiadoras, nesse caso, foi oferecer esses imóveis em leilões, fazendo com que o preço desses ativos reduzisse. O ciclo de valorização dos imóveis deu lugar a um ciclo deflacionário, que comprometeu instituições financeiras de grande porte e 0 funcionamento do mercado de crédito bancário mundial.

\subsection{Participação das instituições privadas na crise de 2008}

O crescimento dos créditos subprime teve seu financiamento baseado em adição de títulos no mercado de capitais, como observam Borça Júnior e Torres Filho (2009). Foi nesse momento que grandes bancos, agências classificadoras de risco americanas e corretoras tiveram um papel decisivo.

Iniciava-se o processo, quando ocorria a transferência de diferentes contratos de hipoteca, para determinado fundo de investimento, conhecido como mortgage pool. O mesmo era responsável por emitir cotas, conhecidas como tranches, de diferentes classes, como relatam Borça Júnior e Torres Filho: "cada uma possuía determinada taxa de retorno diretamente proporcional ao risco assumido pelo seu detentor, isto é, quanto maior o risco de inadimplemento a que o cotista estivesse exposto, maior seria a rentabilidade a que teria direito" (2009, p. 300). O tamanho do risco-retorno de cada tranche era calculado através de modelos estatísticos de gestão de risco, que tinham aceitabilidade das empresas classificadoras.

A responsável por assumir as primeiras perdas, seja por atraso ou por inadimplência, era chamada de patrimônio líquido ou também lixos tóxicos, como mencionam os autores. Quem possuía as cotas por esse risco recebia maior taxa de remuneração e servia de suporte para os demais investidores. Se ocorresse de os prejuízos superarem o patrimônio líquido, o excedente passava a ser responsabilidade dos investidores da classe de risco $\mathrm{B}$.

Conforme os autores, na posição final, encontravam-se as tranches tipo AAA; quem as possuía só obteria prejuízo se todos os demais cotistas houvessem sofrido perdas integrais. Para fins de colocação no mercado de capitais, os bancos dividiam as cotas em três grupos principais: AAA, AA e A, que eram vendidas diretamente ao mercado de investidores. Posteriormente, havia as cotas de risco médio, que eram: B, BB, BBB. Elas eram submetidas a um processo de transformação financeira para melhorar sua respectiva classificação de risco.

Em relação às tranches de risco médio, eram transferidas a um fundo de $\mathrm{CDO}^{15}$ (collateralized debt obligation) com outros títulos de dívida: 
Um fundo de CDO podia, assim, ser composto por direitos sobre milhares de contratos, agrupados de diferentes formas e por meio dos mais diversos instrumentos. Com isso, esperava-se produzir a máxima diluição de risco de cada hipoteca individualmente (BORÇA JÚNIOR; TORRES FILHO, 2009, p. 302).

A partir disso, obtinha-se uma carteira que possuía as melhores classificações de risco.

Inúmeros instrumentos financeiros de diferentes riscos foram combinados pelas agências de rating e por quem fazia a emissão.

As combinações foram realizadas de modo que alguns desses ativos lastreados em hipotecas subprime acabaram reclassificados como de excelente risco ou com grau de investimento. O reempacotamento de hipotecas de alto risco, com a anuência das agências de classificação de risco de crédito, viabilizou suas aquisições pelos investidores com menor aversão ao risco, mas também pelos investidores institucionais, tais como os fundos de pensão e as companhias de seguros, que observam as regras de prudência (CINTRA; CAGNIN, 2007, p. 319).

A decadência dos empréstimos imobiliários de alto risco fez com que as agências de rating rebaixassem inúmeros títulos relacionados às hipotecas subprime, fato que, conforme Freitas (2008), contribuiu para o aumento da incerteza em relação a esses produtos financeiros estruturados.

Segundo Freitas (2008), com o maior enfoque das autoridades de regulamentação no que diz respeito à liquidez e ao capital, os bancos passaram a empregar, de forma crescente, a securitização como ferramenta de administração de balanço. Focados no modelo de modificação das hipotecas em ativos negociáveis da Ginnie Mae e das empresas incentivadas pelo governo, os bancos criaram novos instrumentos de controle financeiro, que ficaram conhecidos como "produtos financeiros estruturados" e tinha como objetivo a construção de um mercado secundário para os empréstimos bancários.

Porém, como destaca o mesmo autor, essas instituições começaram a dar preferência a algumas operações que não constariam no balanço, exemplo disso foram as garantias de créditos e, com isso, a criação de empresas de propósitos especiais, que levaram o nome de Empresas (veículos) de Investimentos Estruturados (SIV). Através desses veículos, os bancos faziam as transferências de parte das suas carteiras no intuito de reduzir as cobranças de capital e a liberação de recursos para novos negócios.

O atrativo nesse meio, como relatam Borça Júnior e Torres Filho (2009), era combinar a alta rentabilidade das cotas de pior risco com as baixas taxas de juros dos comercial papers. Para demonstrar aos investidores que SIVs eram rentáveis, 
os bancos fundadores dessas empresas ampliavam linhas de crédito, que permitiam aos investidores enfrentar as dificuldades de liquidez.

Através da transformação financeira, devido à utilização dos fundos de CDO e de SIVs, os bancos puderam não apenas aumentar os seus níveis de alavancagem, contornando o Acordo de Basileia, mas também transferir os riscos de crédito para o patrimônio dos investidores e para os mercados de capitais. A partir disso, como destacam Borça Júnior e Torres Filho (2009), a seção de créditos subprime compôs uma oportunidade para obtenção de bons retornos, com compensações de risco menores àqueles que teriam de arcar com os prejuízos, se houvesse ausência dos mecanismos de derivativos de crédito analisados.

\section{A expansão da crise no mercado mundial}

O risco do crédito americano foi tomando grandes proporções, atravessou o Atlântico não apenas por via do mercado, como destacam Cintra e Cagnin, mas também por via das instituições, afetando diretamente o setor financeiro Europeu. Os autores relatam que:

Essas conexões podem ser apreendidas em um triângulo de fenômenos: segurança bancária americana, acentuada volatilidade nos mercados europeus de ações e vulnerabilidade em conglomerados financeiros europeus, que combinam operações bancárias e de seguros (bancas surance groups) (2007, p. 318).

Essas ligações com alta complexidade fazem com que o balanço dos bancos corra risco de sofrer aumentos, principalmente dos bancos europeus.

Um forte impacto ocorreu em fevereiro de 2007, quando o HSBC noticiou um balanço com as perdas ocorridas nas operações imobiliárias; em abril do mesmo ano, a empresa New Century Financial, especializada no mercado subprime, quebrou e, consequentemente, demitiu metade de seus funcionários. Em seguida, inúmeros foram os desastres, conforme relata Gontijo (2008):

a) em maio, anunciou-se o fechamento do hedge fund, depois de ter perdido US\$ 125 milhões pela UBS; no mesmo mês, a Moody's, anunciou a queda na classificação de 62 tranches com base em $21 \mathrm{MBSs}$;

b) em junho, a Bear Steams fez o anúncio do resgate de dois dos seus hedge funds e, no dia 18 do outro mês, advertiu investidores que perderiam dinheiro em fundos de derivativos de hipoteca; 
c) nos mesmos meses, a Fitch Ratings, a Standard \& Poor's e a Moody's anunciaram que estavam degradando todos os derivativos de hipotecas de AAA para A+ (quatro graus abaixo);

d) nesse período, o banco hipotecário norte-americano Country Side registrou pesadas perdas;

e) em 6 de agosto, a American Home Mortgage Investment Corporation, anunciou falência, em razão de uma corrida contra seus depósitos;

f) no dia seguinte, o banco alemão IKB Deutsche Industrie Bank AG, que havia sofrido inúmeras perdas, foi resgatado pelo seu maior acionista, a $K f W$ Banken Gruppe;

g) no dia 9 do mesmo mês, o BNP Paribas Investment Partner congelou cerca de US\$ 2,73 bilhões de três de seus hedge funds, relatando não ter condições de avaliar os CDOs em carteira;

h) oito dias depois, o banco alemão Sachsen $L B$ deixou de fornecer a liquidez demandada pelo seu veículo Ormond Quay, incorporada, no final do mês, pelo Landes Bank Baden-Wurttenberg.

Outro banco que revelou perdas de US\$ 3,1 bilhões foi o Citigroup, com uma redução no balanço trimestral de US $\$ 8,7$ bilhões. Conforme Freitas (2008), em 2007, o fundo Abu Dhabi Investment Authority comprou a participação de 4,9\% no capital do Citi, ancorando US\$ 7,5 bilhões. No inicio de 2008, com a divulgação dos dados do quarto trimestre de 2007, o maior banco do mundo em volume de ativos, o Citi, incidiu em prejuízo de US\$ 9,8 bilhões, devido à diminuição de US\$ 18,1 bilhões de títulos de crédito subprime e CDO.

Já no mês de setembro, quem passou a enfrentar dificuldades foi o Banco Lehman Brothers, como enfatizam Borça Júnior e Torres Filho (2008). O banco declarou um prejuízo de US $\$ 3,9$ bilhões no terceiro trimestre de 2008 e, porque o governo não ofereceu apoio financeiro para uma possível aquisição da instituição, o Lehman Brothers solicitou um pedido de concordata na Corte de Falências de Nova York. Marra e Werpel (2011) ressaltam que o principal negociante era o tesouro americano no mercado de valores imobiliários. O governo, não apoiando o Lehman Brothers, fez com que a crise se agravasse ainda mais, gerando medo nos mercados globais.

Com esse pedido de concordata, conforme Lima (2009), surgiu uma reação em cadeia, que tornou pública a situação do sistema financeiro americano. A reação acelerou a queda da seguradora $A I G$ e ocasionou diversos prejuízos, desde prejuízos aos aposentados noruegueses até a investidores do Reserve Primary Fund, um fundo de curto prazo de grande importância, pois apresentava forte seguridade. 
Houve dificuldade de antever os agentes que estariam comprometidos com esse processo, como demonstram Cintra e Cagnin (2007), gerando uma contaminação em outros mercados de títulos. A partir das declarações das quedas de rentabilidade de grandes bancos e de investidores institucionais, interrompeu-se os saques de alguns fundos de investimento. Nesse contexto, os investidores tomaram distância dos títulos garantidos por hipoteca, e houve redução na liquidez do mercado. Houve casos de explosão no prêmio de risco, que teve reprecificação com abrangência global.

\subsection{Incentivos recebidos para combater a crise}

Desde o século XIX até a Grande Depressão ocorrida nos anos de 1930, do século XX, as desvalorizações comprometiam em larga escala os patrimônios privados com rupturas generalizadas de empresas bancárias, industriais e comerciais, como demonstra Braga (2009). Iniciada outra fase de crescimento assumiram a liderança novos empreendedores. Após o desastre dos anos 1930, ficou claro que eventos dessa grandeza poderiam ser evitados, conforme destaca o autor, pelo Big Bank (Banco Central) e pelo Big Government.

Essas intervenções evitaram grandes crises, contiveram recessões, reduziram o desemprego e evitaram grandes depressões, conforme destaca Braga:

[...] foi esse tipo de intervenção que evitou grandes crises, administrou recessões, impediu que se transformassem em depressão, baixou o desemprego, ao custo, entretanto, de tensões inflacionárias, especialmente produzidas pelas defesas das margens de lucro que os oligopólios executavam compensatoriamente durante as apatias na atividade econômica (2009, p. 92).

Os instrumentos monetários utilizados pelo FED para tentar reverter a crise de liquidez, como o fornecimento de crédito para os agentes financeiros e as repetitivas reduções das taxas de juros desde agosto de 2007, como relatam Carcanholo et al. (2008), não foram capazes de desaquecer a crise. A taxa básica de juros dos Estados Unidos foi reduzida fortemente pelo FED, passando de 6,25\%, no mês de agosto de 2007, para $2 \%$, em abril de 2009.

No início de 2008, como mencionam Penin e Ferreira (2008), o Tesouro Americano, com a aceitação do presidente do FED Ben Bernanke, lançou um novo plano econômico, composto pela redução temporária de impostos. Seu principal objetivo foi aumentar a renda disponível às famílias e às empresas e, consequentemente, aumentar os gastos em consumo e investimento, fazendo a sustentação da demanda, agregada, posteriormente, ao crescimento econômico. 
Com estímulos do Tesouro e do FED de 75 bilhões de dólares, a Citigroup, o Bank of America e o JPMorgan / Chase criaram um fundo, como salientam Cintra e Cagnin, conhecido como Master Liquidity Enhancement Conduit, chamado de SuperSiv. Esse fundo iria adquirir papéis lastreados por hipotecas

[...] e evitar que as instituições com títulos invendáveis ou com valor de mercado abaixo do valor de face tenham de se desfazer dos títulos a qualquer preço e de uma única vez, registrando nos seus balanços o prejuízo decorrente das imprudências cometidas durante a farra do crédito imobiliário (2007, p. 322).

Porém, uma onda de turbulências foi desencadeada no mercado financeiro, resultando na perda das ações de grandes instituições financeiras, provocando a queda geral da Bolsa de Valores, como afirma Gontijo (2008). A intervenção do FED, que injetou US $\$ 64$ bilhões no sistema financeiro - pouco tempo depois de o BCU (Banco Central Europeu) alocar U\$\$ 313,1 bilhões e o banco Japonês, US $\$ 13,5$ bilhões -, deu uma tranquilidade ao mercado na metade do mês de agosto.

No dia seguinte ao decreto de falência do Lehman Brothers, o governo modificou sua postura, de acordo com Borça Júnior e Torres Filho (2008). A maior companhia de seguros dos Estados Unidos, a AIG, buscou um empréstimo junto ao FED de cerca de US $\$ 85$ bilhões, devido a sua necessidade de liquidez. Uma possível falência da AIG geraria um forte impacto no sistema financeiro americano, fazendo com que as autoridades monetárias tomassem postura diferente da que a assumida com o Lehman Brothers. Com essa ação, o governo norte-americano tomou o controle de cerca de $80 \%$ das ações da seguradora e do gerenciamento dos seus negócios.

Inúmeras foram às mudanças que aconteceram no sistema financeiro norte-americano. O Bank of America, por cerca de 50 bilhões de dólares, adquiriu o banco de investimento Merril Lynch, como apresentam Borça Júnior e Torres Filho (2008). A JPMorgan, com ajuda financeira dos órgãos federais, assumiu o controle do seu concorrente Washington Mutual. O FED também aprovou a transformação dos bancos de investimento Morgan Stanley e Goldman Sachs em holdings banks, o que permitiu ao FED dar aporte financeiro através de injeções de liquidez.

Com o agravamento da crise de 2008, o Tesouro americano organizou um pacote de incentivos de US $\$ 700$ bilhões, para a compra dos ativos imobiliários que não possuíam liquidez, ação que ficou conhecida como "ativos podres" dos bancos. Essa medida, segundo Borça Júnior e Torres Filho (2008), que retirou os ativos dos balanços das instituições, era uma forma de realizar novos aportes de capital nas instituições financeiras, criando alguma margem às diretrizes dos bancos.

Esclarecem Borça Júnior e Torres Filho (2009) que o FED criou uma linha de crédito, objetivando a compra direta de comercial papers das empresas americanas, 
com a finalidade de garantir, de maneira rápida e direta, a continuidade das operações de capital de giro e a criação de uma linha de crédito aos financiadores do mercado monetário americano, conhecidos como Money markets funds.

As autoridades continuaram tomando medidas para conter a crise financeira. Após as aquisições de ações pontuais isoladas de maneira conjunta, os principais bancos centrais do mundo decidiram cortar 0,5 p. p. em suas taxas básicas de juros. Conforme Borça Júnior e Torres Filho, foi feito um plano de ação pelos principais líderes das economias desenvolvidas, que contemplava não apenas a injeção de liquidez nos mercados de crédito, mas também "garantias dos depósitos bancários, e, até mesmo, a possibilidade da compra de ações de instituições financeiras privadas" (2008, p. 133).

É notável que, após a quebra do Lehman Brothers, o descuido com a política monetária norte-americana e outras medidas de injeção de liquidez criaram uma forte desconfiança em relação a real situação dos bancos, como mostram Borça Júnior e Torres Filho (2009). O ocorrido fez com que aumentasse a tomada de recursos de curto prazo nos mercados interbancários. Um aumento considerável na percepção de riscos dos bancos e na efetivação de empréstimos entre si, faz com que a TED spread atingisse 4,64\% a.a., provocando uma espécie de paralisação das transações entre os bancos.

Desde o início da crise, como mencionam os autores, o aumento da liquidez da economia americana realizou-se em duas frentes diferentes da autoridade monetária. Em primeiro lugar, ocorreu através da diminuição da parcela de títulos do Tesouro Americano em sua carteira, em que os mesmos foram trocados por créditos privados com menor liquidez do que apresentavam nas carteiras dos bancos. E, em segundo lugar, ocorreu pela elevação do volume de crédito do setor privado, através da utilização de instrumentos, como operações compromissadas e leilões de crédito.

\subsection{Consequências no Mercado Mundial}

A crise de 2008 atingiu todos os mercados, do monetário ao de crédito, das bolsas de valores e de mercadorias às operações com opções de compra, de contratos futuros e de swaps, envolvendo, até mesmo, instituições não financeiras, como é o fato das companhias seguradoras e construtoras. Faria (2009) descreve que, em vez de terem expandido para financiar a produção, esses mercados tiveram o seu crescimento em sentido inverso, acumulando ativos em situação duvidosa ao multiplicar operações especulativas e de curto prazo, que lesionaram os investimentos produtivos de médio e longo prazo. 
$\mathrm{Na}$ eclosão da crise, observando a necessidade de regulação do mercado, os governos viram a urgência de quatro importantes ações, como demonstra Bresser-Pereira (2009). Em primeiro lugar, era preciso aumentar a liquidez através da redução da taxa de juros e por todos os outros meios disponíveis. Em segundo, era preciso resgatar e capitalizar os grandes bancos. Em terceiro, era preciso adotar políticas fiscais expansionistas, que se tornaram inevitáveis no momento em que a taxa de juros chegou à zona de armadilha da liquidez. E, em quarto lugar, era preciso fazer a regulamentação do sistema financeiro, doméstico e internacional.

O desenrolar da crise, como mencionam Farhi et al. (2009), colocou em risco a arquitetura financeira internacional no momento em que se tornou explícita as limitações dos princípios básicos do sistema de regulamentação e supervisão bancária e financeira. A intensidade da crise de 2008, que incide, em grande parte, do sistema financeiro mundial, como expõe Mazzucchelli (2008), impactou o progresso dos agregados macroeconômicos reais, como produção, emprego e investimento.

A série de falências, de intervenções e de vendas sobre pressão, como relata Carvalho (2009), espalhou a desconfiança. Não apenas no mercado financeiro, mas também na sociedade em geral, que passou a temer por suas economias. Os países emergentes sentiram o impacto da crise de 2008 gradualmente, basicamente em duas vertentes, como descreve Dulci (2009): por um lado no crédito, que foi dificultado no mercado interbancário e no fluxo dos bancos para as empresas; e, por outro lado, na redução dos preços dos produtos básicos, utilizados para a exportação, como as commodities, que haviam atingido elevadas cotações no início de 2008.

Singer destaca que, em momentos de crise econômica, a incerteza diante do cenário faz com que a população entesoure sua riqueza líquida no lugar de investi-la ou de colocá-la à disposição de quem tem interesse em aplica-la no sistema financeiro. Um momento delicado é a ocorrência da fuga de capitais, quando as filiais de transnacionais fazem a transferência de grande quantidade à matriz, objetivando cobrir prejuízos e cumprir obrigações:

A fuga de capitais reduz a disponibilidade de divisas, levando à desvalorização da moeda nacional ante as moedas que estão sendo retiradas do país e consequentemente a fortes pressões inflacionárias decorrentes da elevação dos preços de todos os produtos importados (SINGER, 2009, p. 97).

Essa situação acometeu alguns países da América Latina, quando eclodiu a crise em 2008.

Os efeitos da crise, inegavelmente, atingiram com intensidade a economia brasileira, como relata Costanzi (2009). Verifica-se sua atuação em três principais canais. Em primeiro lugar, houve uma forte contração no crédito, devido ao aumento 
da aversão ao risco, que afetou de forma intensa os setores de consumo que dependem significativamente do crédito. Em segundo, houve uma queda grandiosa nas expectativas, que impactou fortemente na queda dos investimentos sobre a indústria, afetando a produção de bens de capital. E em terceiro lugar, devido à recessão econômica mundial, houve a redução da quantidade física de exportação pelo Brasil, além disso, ocorreu uma redução dos preços dos produtos vendidos ao exterior.

O cenário macroeconômico sofreu significativas mudanças após a quebra do Lehman Brothers e da intensificação da crise financeira internacional, como descrevem Mesquita e Tóros (2010). Esse cenário de crise desencadeou um processo de "aperto" das condições financeiras em dólares e em reais. Também atuou negativamente sobre a confiança e a atividade econômica, como destacam os autores. A crise atingiu o âmbito internacional e foi muito intensa, gerou um indício da escassez global de liquidez em dólares e piorou os termos de troca, devido à queda dos preços das commodities.

\section{Considerações finais}

A crise financeira, que teve sua origem no mercado imobiliário norte-americano, em meados de 2007, envolveu economias desenvolvidas e em desenvolvimento de diferentes formas. A globalização comercial e financeira e a importância dos Estados Unidos na economia global fez com que a crise tomasse grandes proporções.

A crise financeira de 2008 foi considerada a maior crise desde a grande depressão de 1929. Seu surgimento, após o colapso da bolha imobiliária, foi alimentado pela expansão do crédito bancário e fortificado pela utilização de novos instrumentos financeiros. Intensificou-se no momento da falência do Banco de Investimento Lehman Brothers, no mês de setembro de 2008, após o FED recusar socorrer a instituição. O impacto sobre a confiança dos mercados financeiros foi intenso, rompendo com a ideia de que as autoridades monetárias dos Estados Unidos fossem socorrer todas as instituições financeiras afetadas pela bolha financeira.

O pânico gerado entre as instituições financeiras resultou em um aumento de grande significância na preferência pela liquidez. A procura pela liquidez destruiu o processo de venda de ativos em grande escala, ocasionando a queda nos preços dos ativos financeiros e a contração do crédito bancário, tanto para transações comerciais, como para industriais. Essa ocorrência ocasionou a queda na produção industrial e no comércio internacional de modo global. 


\title{
Origin, causes and impacts of the 2008 financial crisis
}

\begin{abstract}
The crisis demonstrate a not normal situation, as it does not break just received prosperity and enjoyed to that time, it creates a set of shortages and difficulties for the most majority of those involved. The occurrence of a financial crisis can easily understand how disruptions in the economy that are grounded on economic events. The 2008 crisis represented a change in the history of capitalism, reaching all markets, money to credit, stock exchanges and goods. The crisis has reached the international level and had its very intense appearance, generating an indication of the global shortage of the liquidity in dollars and making worse the terms of trade due to falling commodity prices. The American financial bubble was considered the greatest crisis since the Great Depression of 1929 .
\end{abstract}

Keywords: 2008 Crisis. Consequences. Reasons. Impacts.

\section{Origen, causas y los impactos de la crisis financiera del 2008}

\section{Resumen}

La crisis muestra una situación anormal, ya que no se rompe simplemente prosperidad recibido y disfrutado hasta la fecha, se crea un conjunto de carencias y dificultades para la gran mayoría de los involucrados. La ocurrencia de una crisis financiera puede entender fácilmente cómo las interrupciones en la economía que se basan en los acontecimientos económicos. La crisis de 2008 representó un cambio en la historia del capitalismo, llegando a todos los mercados, el monetaria hasta el crédito, bolsas de valores y bienes. Esto ha alcanzado el nivel internacional y tuvo su aparición muy intenso, lo que genera una indicación de la escasez mundial de liquidez en dólares y empeorar la relación de intercambio debido a la caída de los precios de las commodities. La burbuja financiera estadounidense fue considerada la mayor crisis desde la Gran Depresión de 1929.

Palabras clave: Causas. Consecuencias. Crisis de 2008. Impactos. 


\section{Notas}

1 Banco de Crédito Imobiliário Federal.

2 Corporação de Recriação de Finanças.

3 Associação de Hipotecas Federal.

4 Administração de Habitação Federal.

5 Lei Nacional de Habitação.

6 Lei de Reajuste de Militares.

7 Administração de Veteranos.

8 Conselho Federal de Banco.

9 Corporação de Empréstimos de Hipoteca Federal.

10 Associação de Poupança e Empréstimo.

11 Corporação de Poupança e Empréstimos Federais.

12 Títulos lastreados em Hipotecas.

13 Títulos lastreados em Hipotecas Residenciais.

14 Corporação Federal de Depósito Seguro.

15 Obrigação de dívida com garantia.

\section{Referências}

ACCURSO, C. F. Indústria e crise atual. Análise Econômica, Porto Alegre, v. 1, n. 1, p. 77-104, 1983. Disponível em: <http://www.seer.ufrgs.br/index.php/AnaliseEconomica/issue/view/810>. Acesso em: 27 mar. 2014.

BRAGA, J. C. Crise sistêmica de financeirização e a incerteza de mudanças. Estudos Avançados, São Paulo, v. 65, n. 23, p. 89-102, 2009. Disponível em: <http://www.scielo.br/pdf/ea/v23n65/ a06v2365.pdf>. Acesso em: 19 jun. 2014.

BRESSER-PEREIRA, L. C. A Crise financeira global e depois: um novo capitalismo? Novos Estudos, São Paulo, v. 86, p. 51-72, 2010. Disponível em: <http://www.scielo.br/pdf/nec/n86/n86a03. pdf>. Acesso em: 19 mar. 2014.

A insuficiente política econômica em resposta à crise financeira de 2008. Economia \& Tecnologia, Curitiba, v. 18, n. 5, p. 5-16, 2009. Disponível em: <http://ojs.c3sl.ufpr.br/ojs/index. php/ret/article/viewFile/27129/18057>. Acesso em: 02 jun. 2014.

BORÇA JÚNIOR, G. R.; TORRES FILHO, E. T. Analisando a crise do subprime. Revista do BNDES, Rio de Janeiro, v. 15, n. 30, p. 129-159, 2008. Disponível em: <http://www.bndes.gov. br/SiteBNDES/export/sites/default/bndes_pt/Galerias/Arquivos/conhecimento/revista/rev3005. pdf>. Acesso em: 18 abr. 2014.

As Origens e desdobramentos da crise do subprime. In: FERREIRA, F. M. R.; MEIRELLES, B. B. (Org.). Ensaios sobre a economia financeira. Rio de Janeiro: BNDES, 2009. Disponível em:<http://www.bndes.gov.br/SiteBNDES/export/sites/default/bndes_pt/Galerias/Arquivos/ conhecimento/livro/EnsaioEconFinanceira.pdf\#page=287>. Acesso em: 20 abr. 2014.

CARCANHOLO, M. et al. Crise financeira internacional: natureza e impacto. Instituto de Economia. Rio de Janeiro, p. 1-5, 2008. Disponível em: <http://www.ie.ufrj.br/hpp/intranet/pdfs/crise_financeira_internacional_gep_maio_2008.pdf>. Acesso em: 7 maio 2014. 
CARVALHO, F. C. Entendendo a recente crise financeira global. Ibase, Rio de Janeiro, p. 1-5, 2009. Disponível em: <http://www.ppge.ufrgs.br/akb/clipping/9.pdf>. Acesso em: 2 maio 2014.

CINTRA, M. A. M.; CAGNIN, R. F. Evolução da estrutura e da dinâmica das finanças norte-americanas. Revista Econômica, Rio de Janeiro, v. 9, n. 2, p. 296-338, 2007. Disponível em:<http:// www.uff.br/revistaeconomica/v9n2/cintra92.pdf>. Acesso em: 1 maio 2014.

COSTANZI, R. N. Crise global e impactos no Brasil: o problema da estabilidade da instabilidade financeira. FIPE, São Paulo, n. 347, p. 14-19, 2009. Disponível em: <http://www.fipe.org.br/publicacoes/downloads/bif/2009/8_14-19-rog.pdf>. Acesso em: 15 jun. 2014.

DULCI, O. S. Economia e política na crise global. Estudos Avançados, São Paulo, v. 23, n. 65, p. 105-119, 2009. Disponível em: <http://www.scielo.br/pdf/ea/v23n65/a08v2365.pdf>. Acesso em: 18 maio 2014.

FARIA, J. E. Poucas certezas e muitas dúvidas: o direito depois da crise financeira. Revista Direito GV, São Paulo, v. 5, n. 2, p. 297-324, jul./dez. 2009. Disponível em: <http://www.scielo.br/pdf/ rdgv/v5n2/02.pdf>. Acesso em: 20 maio 2014.

FARHI, M. et al. A crise e os desafios para a nova arquitetura financeira internacional. Revista de Economia Política, São Paulo, v. 29, n. 1, p. 135-138, 2009. Disponível em: <http://www.scielo. br/pdf/rep/v29n1/08.pdf >. Acesso em: 08 maio 2014.

FREITAS, M. C. P. de. A origem e desdobramentos da crise do mercado de hipotecas de alto risco nos Estados Unidos. Economia Internacinal (FUNDAP), São Paulo, n. 1, p. 9-24, 2008. Disponível em: <http://www.fundap.sp.gov.br/debatesfundap\%5Cpdf\%5CLivro-Panorama_das_Economias_Internacional_e_Brasileira/01_Crise\%20do\%20mercado\%20de\%20hipotecas.pdf>. Acesso em: 19 mar. 2014.

GONTIJO, C. Raízes da crise financeira dos derivativos subprime. Texto para Discussão (UFMG), Belo Horizonte, n. 342, p. 1-38, 2008. Disponível em: <http://web.face.ufmg.br/cedeplar/site/pesquisas/td/TD\%20342.pdf>. Acesso em: 19 mar. 2014.

GREENSPAN, A. A Era da Turbulência: as aventuras em um novo mundo. Rio de Janeiro: Elsevier, 2008.

KAMINSKY, G. L.; REINHART, C. The twin crises: the causes of banking and balance-of-Payments problem. International Finance Discussion Papers, Washington, n. 544, p. 1-28, 1996. Disponível em: <http://www.federalreserve.gov/pubs/ifdp/1996/544/ifdp544.pdf>. Acesso em: 23 ago. 2014.

KAMINSKY, G. L; REINHART, C.; VÉGH, C. A. The unholy trinity of financial contagion. Journal of Economic Perspectives, Pittsburgh, v. 17, n. 4, p. 51-74, 2003. Disponível em:<http://www. nber.org/papers/w10061.pdf>. Acesso em: 20 ago. 2014.

LIMA, M. C. A crise financeira de setembro de 2008 é também uma crise de paradigma. Teoria e Pesquisa: Revista de Ciência Política, São Carlos, v. 18, n. 2, p. 77-93, jul./dez. 2009. Disponível em: <http://www.teoriaepesquisa.ufscar.br/index.php/tp/article/viewFile/184/150>. Acesso em: 7 maio 2014 .

LIN, W. L.; ENGLE, R. F.; ITO, T. Do bulls and bears move across borders? International transmission of stock returns and volatility as the world turns. National Boreau of Economic Research. Working Paper, Cambridge, n. 3911, p. 1-37, 1991. Disponível em: <http://www.nber.org/ papers/w3911.pdf>. Acesso em: 19 ago. 2014. 
LOBÃO, J. F. S. S. M. Contágio entre mercados de ações de países desenvolvidos: um estudo de processos de transmissão de choque de rendibilidade num contexto de episódio de crises financeiras. 2007. 385 f. Tese (Doutorado em Economia), Universidade do Minho, Braga, 2007. Disponível em: <http://www.eumed.net/tesis/2009/jfssml/Canais\%20de\%20Contagio.htm>. Acesso em: 21 out. 2014.

MARRA, V. N.; WERPEL, F. J. F. O labirinto da crise financeira de 2008. Idea, Uberlândia, v. 2, n. 2, p. 1-18, jan./jul. 2011. Disponível em: <http://esamcuberlandia.com.br/revistaidea/index.php/idea/article/view/38/39>. Acesso em: 15 maio 2014.

MAZZUCCHELLI, F. A crise em perspectiva: 1929 e 2008. Novos Estudos, São Paulo, v. 82, p. 57-66, nov. 2008. Disponível em: <http://www.scielo.br/pdf/nec/n82/03.pdf>. Acesso em: 18 maio 2014.

MESQUITA, M.; TORÓS, M. Considerações sobre a atuação do banco central na crise de 2008. Trabalhos para discussão (Banco Central do Brasil), Brasília, n. 202, p. 3-39, 2010. Disponível em: <http://www.bcb.gov.br/pec/wps/port/wps202.pdf>. Acesso em: 19 maio 2014.

PENIN, G.; FERREIRA, T. T. Boletim Fipe. São Paulo: Evolução recente da crise do subprime: indicadores, reações e perspectivas, 2008. p. 16-20. Disponível em: <http://www.fipe.org.br/publicacoes/downloads/bif/2007/10_25-29-ferr.pdf>. Acesso em: 17 maio 2014.

REINHART, C. M.; ROGOFF, K. S. The aftermath of financial crises. Working Paper, Cambridge, n. 14656, p. 2-13, jan. 2009. Disponível em: <http://www.nber.org/papers/w14656.pdf>. Acesso em: 23 ago. 2014.

SINGER, P. A América Latina na crise mundial. Estudos Avançados, São Paulo, v. 66, n. 23, p. 91-102, 2009. Disponível em: <http://www.scielo.br/pdf/ea/v23n66/a08v2366.pdf>. Acesso em: 2 jun. 2014. 